\title{
O português do(a) surdo(a) no rizoma das línguas brasileiras
}

Hildomar José de Lima ${ }^{1}$

Tânia Ferreira Rezende ${ }^{2}$

Resumo: A concepção de português brasileiro está vinculada à racionalidade científica eurocêntrica que mantém a geopolítica das línguas brasileiras com base no poder político da língua imperial, do colonizador e da colonização. Esse pensamento ocidental determina a importância política tanto da escrita sobre a oralidade quanto da língua oral falada por uma minoria de brasileiros(as) em relação ao português como língua de tantas outras comunidades linguísticas e estabelece uma lógica de organização hierárquica vertical das línguas brasileiras. Essa forma de estratificação política das línguas opera para a manutenção da colonialidade do poder, do saber e da linguagem sobre povos historicamente subalternizados. Com base nas noções de "árvore-raiz" e de "raiz-fasciculada" (DELEUZE; GUATTARI, 2011), busca-se refletir sobre a construção ideológica do monolinguismo brasileiro a partir de posturas políticas que instituem o poder imperial do português brasileiro numa organização sociolinguística pluri/multilíngue. A partir dessa reflexão, propõe-se uma ampliação teórica da noção de "rizoma" (DELEUZE; GUATTARI, 2011) para o contexto da política linguística como alternativa à supervalorização de uma língua em detrimentos de outras que coexistem num mesmo território. Na perspectiva rizomática de língua, o português do(a) surdo(a), bem como o português de outras comunidades linguísticas historicamente subalternizadas, se insere no rizoma linguístico brasileiro para desestabilizar a hegemonia e a colonialidade linguística e dar visibilidade para uma nova geopolítica das línguas brasileiras.

Palavras-chave: Colonialidade da linguagem. Português do(a) surdo(a). Rizoma linguístico.

\section{Deaf people Portuguese in the rhizome of Brazilian languages}

\begin{abstract}
The conception of Brazilian Portuguese is linked to the eurocentric scientific rationality that keeps the geopolitics of Brazilian languages based on the political power of the imperial language, from the colonizer, and the colonization. This Western thought determines the political importance of writing about orality as well as of the oral language spoken by a minority of Brazilians in relation to Portuguese as a language of so many other linguistic communities and establishes a logic of vertical hierarchical organization of Brazilian languages. This form of political stratification of languages operates for the maintenance of the coloniality of power, knowledge and language over historically subalternized peoples. Based on the notions of "root-tree" and "fasciculated-root" (DELEUZE; GUATTARI, 2011), we look to reflect on the ideological construction of Brazilian monolingualism from political postures that institute the imperial power of Brazilian Portuguese in a pluri/multilingual sociolinguistic organization. From this reflection, we propose a theoretical extension of the notion of "rhizome" (DELEUZE; GUATTARI, 2011) for the context of linguistic policies as an alternative to the supervaluation of a language over others that coexist in the same territory. In the rhizomatic perspective of language, the deaf people Portuguese, as well as the Portuguese of other historically subalternized linguistic communities, is inserted in the Brazilian linguistic rhizome to destabilize the hegemony and the linguistic coloniality and give visibility to a new geopolitics of the Brazilian languages.
\end{abstract}

Keywords: Coloniality of language. Deaf people Portuguese. Linguistic rhizome.

\footnotetext{
${ }^{1}$ Professor do Departamento de Libras e Tradução da Faculdade de Letras da Universidade Federal de Goiás. E-mail: hildomar_lima@ufg.br.

${ }^{2}$ Professora do Departamento de Linguística e Língua Portuguesa e do Programa de Pós-Graduação em Letras e Linguística da Faculdade de Letras da Universidade Federal de Goiás. E-mail: taferez@ufg.br.
} 


\section{Rimivarions}

ista Eletrônica de Graduação e Pós-Graduação em Educação

\section{INTRODUÇÃO}

A matriz curricular da atualidade é um espaço de disputa política entre o idioma da Constituição, a Língua Portuguesa, e o português brasileiro supostamente tido como língua materna de todos os povos do país. Embora as realidades sociolinguística e sociocultural brasileira confrontem essa competição política, um português hegemônico é mantido como "instrumento" de acesso aos conteúdos escolares, documentos jurídicos etc. e, desse modo, tornado a língua do "pleno exercício da cidadania", que oprime e subalterniza povos brasileiros ainda no século XXI, em meio a uma diversidade expressiva de povos com diferentes línguas e culturas.

Por mais paradoxal que pareça, a luta política pela emergência do português brasileiro preserva fortes traços de atitudes e posturas linguísticas do século XVI, ou seja, mantém o status de língua imperial (colonialidade linguística). Do ponto de vista das políticas de educação linguística, a manutenção da colonialidade linguística pelo Estado é um fator preocupante e, por isso, merece ser retomado para mais discussões como forma de assegurar os direitos linguísticos de povos historicamente subalternizados. Assim, este texto aponta especialmente os povos indígenas, quilombolas e a pessoas surdas como grupos que constituem e sustentam a pluralidade linguístico-cultural brasileira, revelando identidades linguísticas que promovem, segundo a visão de Lima e Rezende (2019, no prelo), o "translinguajamento" e a "transmodalidade". Para esse autor e essa autora, "as pessoas surdas estão imersas em constantes e contínuos processos de translinguajamento e transmodalidade, isso é, em trânsito entre línguas (sinais e orais) e entre modalidades linguísticas (visuoespacial e oral-auditiva) (ibid., p. 1).

Indígenas, surdos(as) e quilombolas, bem como diversos outros povos, falam o português, no entanto, pertencem a mundos de significações diferentes. Pinto (2013, p. 134) argumenta que a política de homogeneização das línguas se revela na "falácia da prefiguração identitária", no sentido de não haver uma convergência para a diferença entre os povos e suas línguas. Na visão da autora, essa falácia fortalece "a diferença entre o 'culto' e o 'popular', a força do português europeu contra a simplificação africana e indígena". A prefiguração identitária concretiza uma violência epistêmica a partir da lógica de que língua oral, como no 


\section{MTiparius REFLECTIONIS}

Revista Eletrônica de Graduação e Pós-Graduaçāo em Educaçäo

caso do português, é coisa de ouvinte, fortalecendo, assim, a relação de poder entre ouvintes e surdos(as).

E é essa língua da - e para a - pessoa ouvinte idealizada pelas práticas linguísticas que determina a divisão geopolítica das línguas brasileiras, que ainda são vistas numa relação hierárquica vertical. Essa lógica de organização política das línguas opera para a manutenção da colonialidade do poder (QUIJANO, 2009; 2005; 2000), do saber (LANDER, 2005) e da linguagem (GARCÉS, 2007). No contexto dessa discussão, a colonialidade do poder refere-se especialmente à hierarquização e à classificação social entre pessoas ouvintes e surdas, bem como de suas línguas. A lógica da colonialidade do poder transpõe-se para o campo do saber, que busca legitimar a racionalidade científica "euro-ouvintista" (LIMA; REZENDE, 2018) como perspectiva superior do conhecimento. A colonialidade do saber, por sua vez, invade o universo da linguagem, que atesta uma língua como válida para a produção e para a gestão do conhecimento. Lima e Rezende (2018) denominam "euro-ouvintismo" a racionalidade eurocêntrica que vem, ao longo dos tempos, imprimindo na pessoa surda um jeito ouvinte de ser, de pensar e de lidar com o mundo da oralidade.

Neste artigo, busca-se refletir sobre a lógica subversiva da política da diversidade linguística a partir da noção de português brasileiro como língua que representa todas as comunidades de fala do país. A discussão parte da concepção de "árvore-raiz" e de "raizfasciculada", que contrapõe a ideia de "rizoma", proposta por Deleuze e Guattari (2011). Entende-se, com base nesses autores, que pensar a pluralidade linguística em forma de raiz é delimitar em torno de uma língua a organização sociolinguística de um país que concentra uma das maiores diversidades linguísticas do mundo e, com isso, produzir ideologicamente uma nação monolíngue.

Em contrapartida, desenvolver a concepção de rizoma no campo da Linguística, diferentemente da perspectiva que se tem no campo da botânica, é construir um pensamento que compreenda a "multiplicidade", contribuindo, assim, para o entendimento da importância da coexistência entre as línguas e consequentemente uma maior aceitação entre os povos. Deleuze e Guattari (2011, p. 41) se referem a rizoma como um esquema de pensamento ao mencionarem que

os reis da França escolhem o lírio, porque é uma planta com raízes profundas prendendo os talos. Seria a mesma coisa no Oriente? Seguramente, é muito mais fácil apresentar um Oriente de rizoma de imanência; mas o Estado não age nele segundo um esquema de arborescência correspondente a classes preestabelecidas, 
arborificadas e enraizadas: é uma burocracia de canais, por exemplo, o famoso poder hidráulico feito de "propriedade fraca", onde o Estado engendra classes canalizantes e canalizadas

Pensar na diversidade linguística brasileira a partir de uma racionalidade rizomática é confrontar a política ideológica do Estado que engendra a visão em torno da crença de que há uma só raça, com uma só língua, e desestabilizar a hegemonia do pensamento "arborescente" euro-ouvintista em relação à domesticação linguística das pessoas surdas, especialmente no que se refere às práticas escritas em português. Propomos discutir nas seções seguintes: (i) como a implementação de um projeto que estabelece a norma linguística urbana culta do Brasil sustenta a hegemonia geral que insiste em criar falantes ideais com base em uma língua também idealizada, (ii) o português brasileiro como proposta contra-hegemônica de língua que, na verdade, perpetua a colonialidade linguística no Brasil, (iii) a concepção de rizoma linguístico como fundamento político, epistêmico e linguístico para a desestabilização da hegemonia e da colonialidade linguística e, por fim, (iv) como o português do(a) surdo(a) se insere no rizoma linguístico brasileiro.

\section{A DIVERSIDADE LINGUÍSTICA BRASILEIRA EM FORMA DE ÁRVORE-RAIZ}

Embora se tenha buscado nos últimos anos reconhecer e valorizar a diversidade linguística brasileira, o muito que se conseguiu fazer foi provavelmente subverter a equação da lógica binária um devém dois, discutida por Deleuze e Guattari (2011, p. 19), que preside a divisão geopolítica das línguas no Brasil. Esses autores partem da proposição "o livro imita o mundo, como a arte, a natureza" e mostram que a própria lei do livro, a reflexão ("o Uno que se devém dois"), subverte a ordem e promove a fragmentação entre "mundo e livro, natureza e arte".

Essa equação possibilita refletir o português brasileiro como língua que se levanta contra a diversidade linguística brasileira na mesma proporção que o faz o português da colonização, que é mantido como ideal de língua na matriz curricular. O português colonial e o português brasileiro, que correspondem em proporção à lógica "um devém dois", vêm tornando o Brasil um cenário geopolítico de controle linguístico que se consolida a partir de políticas linguísticas que sustentam um português idealizado, como defende Carneiro (2006), como "vetor linguístico" tanto para representar todas as comunidades de fala como para validar a produção de conhecimento. 


\section{ITHerapus REFLECTIONIS}

Revista Eletrônica de Graduação e Pós-Graduaçāo em Educaçäo

O discurso político de que era preciso ter uma língua mais próxima dos falantes de português no Brasil elucidou para um grupo de teóricos da linguagem a necessidade de se pensar um projeto de língua que visasse superar o padrão culto decretado pela coroa real, impondo, em contrapartida, a norma culta do português supostamente falado no Brasil (SILVA, 1996). No entanto, torna-se necessário subverter a equação "português brasileiro" como forma de insubordinar uma diversidade de povos e suas línguas que estão subclassificadas geopoliticamente pelo Projeto da Norma Linguística Urbana Culta do Brasil.

Esse projeto estabelece um português como sendo dos(as) brasileiros(as), instituindo, assim, uma política linguística unificadora e, por isso, excludente, que se implementa, desde o final da década de 1960, em amostragens coletadas de um português falado por um grupo linguístico considerado potencialmente distinto (é preciso, por exemplo, ter nível superior completo) de cinco centros urbanos do país, a saber: Recife, Salvador, Rio de Janeiro, São Paulo e Porto Alegre, dominados pelas portas da colonização. Com base na discussão de Deleuze e Guattari (2011, p. 20), diz-se aqui que "este pensamento nunca compreendeu a multiplicidade: ele necessita de uma forte unidade principal”. A figura 1, a seguir, mostra a formação da base do valor político atribuído ao português brasileiro.

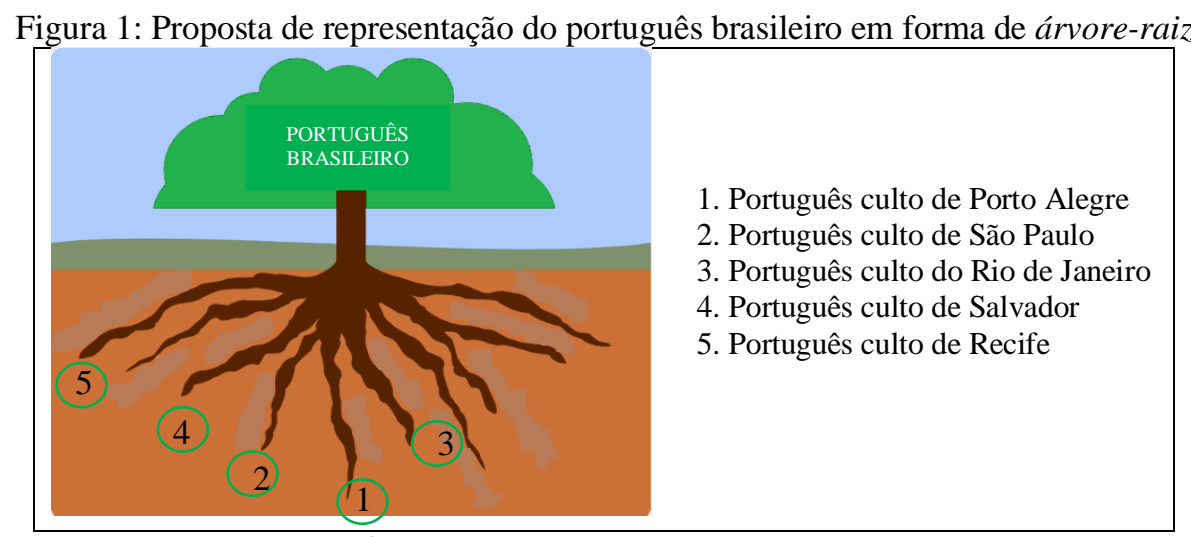

Fonte $^{3}$ : Instituto Socioambiental. (Adaptado).

Essa figura auxilia no entendimento de que, mesmo afirmando uma língua falada por pessoas que vivenciam experiências sociolinguísticas brasileiras, tem-se um português como, conforme os termos de Deleuze e Guattari (2011, p. 23), "língua-mãe", definido com base em pequenas amostras, que exclui uma diversidade de povos que falam português, entre eles(as), os(as) indígenas, os(as) surdos(as), os(as) quilombolas. Esses grupos não se

\footnotetext{
3 Imagem ilustrativa retirada do endereço eletrônico: https://mirim.org/linguas-indigenas/troncos-familias. Acesso em: 15 fev. 2019.
} 
encaixam nos critérios definidos no projeto de língua para os(as) brasileiros(as), especialmente pelo fato de essas pessoas não terem passado pelos centros de poder - as universidades/instituições de ensino - onde se preserva um dos grandes legados trazidos nas navegações que chegaram pelo Atlântico - a língua da civilização. Quem não passa por esses centros não tem um português "puro". Essa parece ser uma lógica óbvia para o projeto.

É também com base na ideia de português brasileiro como língua principal, falada por um grupo seleto de falantes, que se propaga o discurso social de que os(as) brasileiros(as) não sabem português. Há nesse discurso uma violência brutal contra os povos historicamente subalternizados, pois ao longo da história são convencidos(as) de que não sabem e não aprenderão essa língua. Esse discurso, o qual não entendemos nem consideramos "senso comum", como aponta Faraco (2012), uma vez que os laços e emaranhados da colonialidade mantêm a linguagem como projeto de subalternização linguística e ontológica de pessoas, ecoa forte de um grupo relativamente pequeno de polícia linguística, isto é, de pessoas que se prestam a manter a ordem linguística colonial.

Os conflitos epistêmicos entre os diferentes grupos de falantes surgem como consequência dessa incapacidade de compreensão da diversidade de línguas que resulta da história linguística homogeneizante do português. Essa história oculta e apaga realidades construídas por meio de experiências sociolinguísticas particulares e múltiplas que são deslegitimadas pela imposição da forma de um português que não os(as) representa.

Observa-se, portanto, que o português se apresenta dividido entre dois polos de influência (a língua do império e a língua de algumas pessoas de cinco centros urbanos brasileiros) e passa a ser visto, nos termos de Bagno (2010), como "entidade bipolarizada" entre norma padrão e norma culta. Tal como aponta esse autor, a norma culta é uma forma possível de uso da língua, porém restrita ao contexto urbano e com falantes em que o nível de escolaridade seja o grau superior, enquanto que a norma padrão não se constitui língua, pois se refere à forma ideal de uso e que deveria ser seguida por todos(as) os(as) falantes. Bagno compara a ideia de língua padrão a um único modelo de sapato e argumenta que é inimaginável pensar que toda a população de um país calçasse o mesmo modelo de sapato.

Cabe, consequentemente, problematizar a ideia de norma culta como forma possível com base em falantes que estão fora do eixo de alcance do português brasileiro, como, por exemplo, as pessoas surdas, entre outras postas anteriormente. Realmente a norma culta do português brasileiro é uma forma possível, mas não para todos(as). Na visão de 


\section{ITHaping REFLECTIONIS}

Revista Eletrônica de Graduação e Pós-Graduaçāo em Educaçäo

Faraco (2012, p. 37), "há na designação norma culta um emaranhado de pressupostos nem sempre claramente discerníveis", especialmente por parte daqueles(as) que falam a língua "certa/idealizada". Isso significa que a norma culta do português brasileiro é também uma forma idealizada, que torna os(as) surdos(as), e também outros povos, "os(as) ignorantes" e “incultos(as)” da língua.

Assim, presume-se que a oposição entre norma padrão e norma culta apenas segue a lógica de organização binária de mundo ("um devém dois"). O português padrão e a norma culta do português brasileiro representam o que Mignolo (2009) descreve como "frame" e "superframe", respectivamente. Pensar o português brasileiro com base apenas nas cinco capitais mencionadas anteriormente, na figura 1, como alternativa contra-hegemônica à influência linguística colonial portuguesa é, sem dúvida, alargar a borda do frame de língua imperial e permanecer no superframe das práticas linguísticas imperialistas. Isso porque o que as comunidades subalternizadas produzem de língua (português) é sempre "analisado" pela metalinguagem de uma língua que não os(as) engloba para mostrar que o que falam é a variante (desvio) de uma língua idealizada e supostamente certa. Isso significa, portanto, que o português brasileiro é ideologicamente um modelo de sapato.

Faraco (2012, p. 36) salienta que para superar o "artificialismo" da nossa língua imposto pelas gramáticas é necessário um projeto que reconstrua as nossas "referências padronizadoras", aceitando, por exemplo, que

os grupos sociais se distinguem pelas formas de língua que lhes são de uso comum. Esse uso comum caracteriza o que se chama de norma linguística de determinado grupo. Assim, numa sociedade diversificada e estratificada como a brasileira, haverá inúmeras normas linguísticas, como, por exemplo, a norma característica de comunidades rurais tradicionais, aquela de comunidades rurais de determinadas ascendência étnica, a norma característica de grupos juvenis urbanos, a(s) norma(s) característica(s) de populações das periferias urbanas, a norma informal da classe média urbana e assim por diante.

É, pois, importante compreender que o português das práticas sociais das diversas comunidades assegura especificidades que são cosmo-epistêmicas e que, por isso, essa língua apresentará traços característicos que remetam à organização sociocultural de cada grupo, visto que recorta realidades distintas (mundos formados a partir de diferentes línguas). Não se trata, portanto, simplesmente em estratificar o português dessas comunidades em variedades do português brasileiro. 


\section{ITHerapuns REFLETIONIS}

Revista Eletrônica de Graduação e Pós-Graduação em Educaçāo

Assim como é necessário pensar em sapatos considerando que existem diferentes tamanhos e formatos de pés, é preciso problematizar esse português brasileiro de minoria, pois as comunidades linguísticas brasileiras, inquestionavelmente diversa, evidenciam que tanto o português da Constituição quanto o português brasileiro estão longe de ser a mesma língua para todos(as). Segundo defendem Deleuze e Guattari (2011, p. 23), "não existe uma língua-mãe, mas tomada de poder por uma língua dominante dentro de uma multiplicidade política”. Dessa forma, torna-se imprescindível problematizar a lógica da organização vertical das línguas brasileiras a partir do português, conforme se discute na próxima seção.

\section{O PORTUGUÊS BRASILEIRO COMO RAIZ-FASCICULADA}

Acreditamos ser importante mencionar o nosso reconhecimento de que refletir o imperialismo do português brasileiro parece, inicialmente, se colocar diante de duas injunções antinômicas. Por um lado, admite-se que confrontar o português europeu foi um ato político importante na história linguística do Brasil. Embora necessária em várias situações linguísticas, a luta política do processo de emergência de uma língua pode ser cruel. Isso porque o presente continua ideologicamente orientado por políticas linguísticas coloniais, ou seja, ainda existe a necessidade de se ter uma língua única. O que significa que a mentalidade linguística no presente é tão colonial como foi no passado.

Por outro lado, para se fazer emergir o português brasileiro, muitas outras línguas (em número maior as indígenas) foram esmagadas. A ideologia linguística dominante que eleva o português brasileiro determina, ao mesmo tempo, a divisão geopolítica das línguas brasileiras a partir do não reconhecimento de inúmeras outras línguas. Essa antinomia nos remete ao "sistema-radícula, ou raiz fasciculada", proposto por Deleuze e Guattari (2011). Retomemos, portanto, a figura 1, reproduzida a seguir como figura 2, para melhor compreender que há uma língua como raiz principal que, na visão desses autores, "abortou, ou se destruiu em sua extremidade: vem se enxertar nela uma multiplicidade imediata e qualquer de raízes secundárias que deflagram um grande movimento” (ibid., p. 20). 


\section{MTHapins REFLECTIONIS}

Revista Eletrônica de Graduação e Pós-Graduação em Educaçäo

Figura 2: Proposta de representação do português brasileiro em forma de raiz-fasciculada

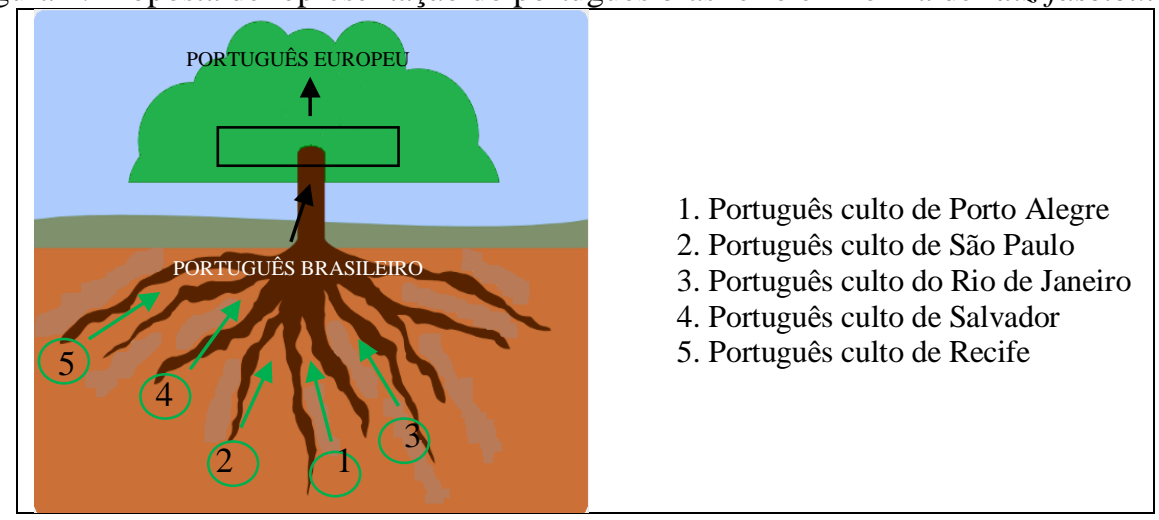

As línguas-raízes que representam parte de cinco centros urbanos se enxertam na unidade principal e passam a representar a diversidade de línguas, tornando o português brasileiro a "língua angelical" e dócil de todos(as) os(as) brasileiros(as), pois como afirmam Deleuze e Guattari (2011, p. 21),

toda vez que uma multiplicidade se encontra presa numa estrutura, seu crescimento é compensado por uma redução de leis de combinação. Os abortadores da unidade são aqui fazedores de anjos, doctores angelici, posto que eles afirmam uma unidade propriamente angélica e superior.

À medida que a raiz principal começa a despontar, ela vai se tornando o “instrumento", por meio do qual muitos povos atingirão a civilidade. Para Calvet (2002), essa é uma visão tradicional de língua. Com isso, a realidade sociocomunicativa de muitos(as) surdos(as), por exemplo, é marcada pelos preconceitos que classificam o seu português como uma forma "rudimentar" de linguagem, uma vez que está determinado que essas pessoas não atingirão o padrão de língua principal, da qual a pessoa surda não pode fazer parte. Sobre isso, Pinto (2013, p. 134) argumenta que

a população brasileira que não aderiu ao padrão do português europeu é "popular" e "iletrada", enquanto a parcela "letrada" e "culta" tem sempre o benefício da dúvida quando usa estruturas "informais" ou "em desacordo com as regras da língua escrita e da gramática tradicional.

Logo, o português brasileiro como raiz-fasciculada é a língua oral que perpetua as heranças da língua do colonizador e da época da colonização, especialmente no que se refere à oralidade e à pessoa ouvinte como um princípio ideológico de língua e de gente, respectivamente. Na visão de Rezende (2011, p. 8), existe uma "política linguística unificadora em torno da língua portuguesa" que estabelece um modelo de ordenação geopolítica das línguas, promovendo hierarquias que operam para a manutenção de um 


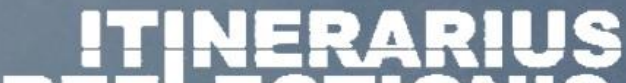 REFLECTIONIS}

Revista Eletrônica de Graduação e Pós-Graduação em Educaçäo

sistema linguístico opressor e excludente. Janson (2015, p. 95) argumenta que nesse processo de hierarquização das línguas

uma ideia recorrente era a de que algumas línguas são civilizadas e desenvolvidas, enquanto outras são bárbaras e primitivas, e essa linha de raciocínio se tornou dominante na Europa durante o século XIX, a era do colonialismo. As línguas dos colonizadores, como o português, o inglês e o francês, eram vista, é claro, como desenvolvidas por definição, enquanto as línguas usadas pelos nativos das colônias eram em sua maioria classificadas como primitivas.

Essa forma de se perceber as línguas, especialmente aquelas historicamente subalternizadas, da perspectiva da ideologia imperial nos convida a retomar uma questão posta por Mignolo (2003, p. 345): “como foi que a literalidade e as gramáticas escritas demarcaram as fronteiras entre línguas e controlaram o fluxo natural do linguajamento sem o policiamento das gramáticas escritas e a política natural da língua?”.

Pois bem, as fronteiras linguísticas são de natureza essencialmente política e sustentam as hierarquias impostas por meio de preceitos normativos estabelecidos com base em situações ideais e irreais de uso com o propósito de criar um falante ideal, insistindo, para tanto, na manutenção de uma língua que funciona para a minoria, negando suas naturezas dinâmica e social. A hierarquização vertical das línguas, maneira como são naturalmente vistas no Brasil, promove naturalmente uma relação de opressão entre as línguas que ocupam o lugar de prestígio, o pivô da pirâmide, e aquelas que estão em posições menos importantes, a parte inferior ou periférica, conforme se observa na figura 3 , a seguir.

Figura 3: Proposta de representação gráfica da hierarquização vertical das línguas no Brasil

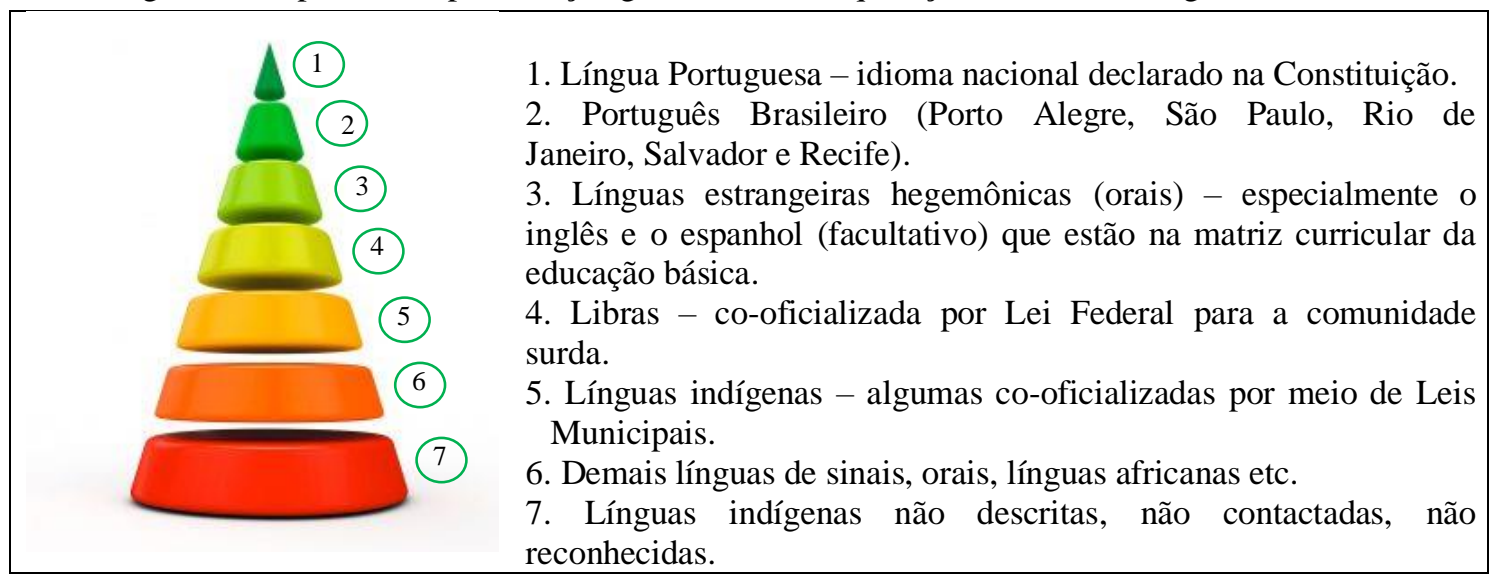

Fonte ${ }^{4}$ : Elaborado pelos autores

\footnotetext{
4 Imagem ilustrativa retirada do endereço eletrônico: https://www.pensamentoverde.com.br/meioambiente/conheca-piramide-de-biomassa/. Acesso em: 10 fev. 2019.
} 


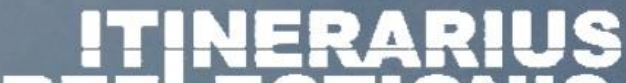 REFLETIONIS}

Revista Eletrônica de Graduação e Pós-Graduação em Educaçāo

Esse modelo de organização linguística motiva e fortalece um dos mitos que rondam as línguas do mundo no qual se estabelece a relação entre a civilização de um povo e a complexidade linguística da língua utilizada por ele (LUCCHESI, 2015, p. 16). Isso significa que tornar linguisticamente complexa uma língua é dar a ela a metalinguagem e a estética necessárias para se atingir o estágio avançado de civilidade dos(as) seus/suas falantes. Complexidade linguística se reduz, nesse caso, ao modelo de língua baseado numa lógica de racionalidade eurocêntrica e euro-ouvintista. A estética, por sua vez, está relacionada aos corpos linguísticos, isto é, quem enuncia e de que lugar se enuncia, e qual é a base política para a estruturação de seus enunciados.

\section{A DIVERSIDADE LINGUÍSTICA BRASILEIRA EM FORMA DE RIZOMA}

Para Deleuze e Guattari (2011), rizoma constitui uma lógica de racionalidade que se organiza a partir da compreensão da "multiplicidade". Esse pensamento é alternativo à razão binária que se estrutura a partir da relação dicotômica "um devém dois" (um-dois). Segundo esses autores, "um rizoma como haste subterrânea distingue-se absolutamente das raízes e radículas” (ibid., p. 21), uma vez que o múltiplo, nesse caso a pluralidade de línguas, não deve ser entendido numa ordenação hierarquizante, como mostra a figura 3 , em que as línguas apresentam níveis diferenciados de importância. Nesse sentido, a perspectiva rizomática desses autores possibilita enxergar a diversidade linguística de forma esparramada.

Deleuze e Guattari enumeram características aproximativas do rizoma que possibilitam o entendimento, por exemplo, de que a "diferença" é um traço que tem como função garantir a harmonia entre as línguas. Os dois primeiros princípios discutidos por esses autores são a conexão ("qualquer ponto de um rizoma pode ser conectado a qualquer outro e deve sê-lo" (ibid., p. 22)) e a heterogeneidade ("a língua é uma realidade essencialmente heterogênea" (ibid., p. 23)). A diversidade linguística brasileira forma um rizoma linguístico em que se é possível observar as várias línguas estabelecendo conexões culturais, sobretudo políticas entre si, conforme se observa na figura 4 , a seguir. 


\section{ITHaRius REFLECTIONIS}

Revista Eletrônica de Graduação e Pós-Graduaçāo em Educaçäo

Figura 4: Proposta de representação da diversidade linguística do Brasil em forma de rizoma

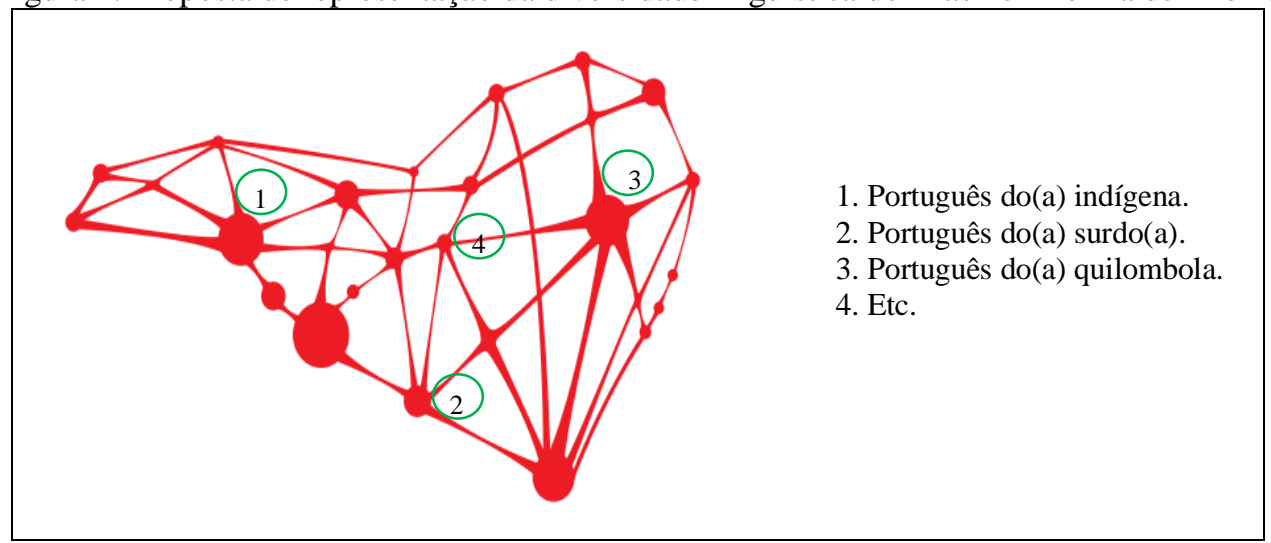

Fonte $^{5}$ : Redes Livres do Brasil. (Adaptado)

Na perspectiva rizomática de língua, cada ponto do rizoma representa uma língua que se conecta a outras, ampliando e diversificando as geopolíticas. Nesse sentido, a concepção de rizoma linguístico amplia nosso entendimento de sincretismo linguísticocultural brasileiro para além da fusão de povos e suas línguas. Cada ponto do rizoma passa, portanto, a compreender um espaço de resistência linguístico-cultural. A ideia de rizoma linguístico constitui, por conseguinte, uma perspectiva epistemológica de organização linguística das populações que falam e escrevem, ou só falam, ou só escrevem o português, possibilitando uma relação simétrica não linear entre os diferentes usos do português e as diferenças epistêmicas dos povos brasileiros, que devem ser igualmente respeitadas e valorizadas.

Os dados do IBGE de $2010^{6}$ indicam que há quase uma década existiam 896.907 (oitocentos e noventa e seis mil e novecentos e sete) pessoas indígenas espalhadas por todos os Estados brasileiros. Esse número comprova que os povos indígenas brasileiros, com suas línguas, são parte fundamental na composição da rica e complexa diversidade linguísticocultural deste país. Com esses povos estão as inúmeras línguas, ou melhor, esses povos são a diversidade linguístico-cultural que sofre, ao longo da história, "um processo violento e massacrante (...) [para] a interiorização do domínio do português" (REZENDE, 2011, p. 4). Suas existências sociolinguísticas definem o complexo translinguajamento dos povos indígenas no Brasil marcado pelo poder imperial do português.

\footnotetext{
${ }^{5}$ Imagem ilustrativa retirada do endereço eletrônico: http://www.redeslivres.org.br. Acesso em: 10 fev. 2019.

${ }^{6}$ Dados do Censo Demográfico realizado pelo Instituto Brasileiro de Geografia e Estatística (IBGE) em 2010. Disponível em: https://ww2.ibge.gov.br/estadosat/. Levantamento realizado em: 12 dez. 2018.
} 


\section{HTiparys REFLECTIONIS}

Revista Eletrônica de Graduação e Pós-Graduaçāo em Educaçäo

Além da pluralidade de línguas indígenas, têm-se ainda as línguas alóctones (de imigração), as línguas de fronteiras, as línguas de sinais e a libras. Há quase uma década os dados do IBGE de 2010 apontaram que, no Brasil, existiam 9.705,566 (nove milhões, setecentos e cinco mil e quinhentos e sessenta e seis) de pessoas surdas ou que apresentam algum tipo de deficiência auditiva. Esses números revelam que as pessoas surdas e suas línguas constroem uma história de pertencimento surdo na sociedade brasileira.

Contrário ao pressuposto monolinguismo brasileiro, a situação sócio-etnocultural dos povos indígenas e das pessoas surdas situa linguisticamente essas e diversas outras comunidades linguísticas brasileiras em relação ao português. Embora as políticas monolíngues insistam em manter o português brasileiro como pivô de língua, o português indígena, o português do(a) surdo(a), do(a) quilombola etc. resistem aos esforços históricos de aniquilamento da diversidade étnico, linguística e cultural no Brasil.

Não há um só povo, portanto, não deve haver um só português para representar cultural e linguisticamente os diversos povos e suas línguas. Reitera-se, portanto, que o português não é a mesma língua para todas as comunidades indígenas, tampouco a mesma para surdos(as) e ouvintes, senão "outra língua, com formas, funções e regras de usos próprios da comunidade que a fala, colore e perpetua" (REZENDE, 2011, p. 5). O português tapuia, por exemplo, é, para Rodrigues (2018, p. 148),

\footnotetext{
(...) a expressão do sentimento de pertencimento ao ser indígena e ao ser Tapuia no Carretão. [...]. A língua de um povo é muito mais que gramática e léxico, é sentimento, é vínculo com o passado, com a realidade e com a irrealidade. Ao reconhecer o Português Tapuia como sua língua indígena, os Tapuias se reconhecem e se assumem, ao mesmo tempo, indígenas e Tapuias. Há uma visível mudança de atitude sociolinguística na comunidade, com relação a ser e a se reconhecer falante de Português Tapuia e com relação a ser Tapuia e, assim, ser indígena. O processo de autoaceitação é o próprio processo de etnogênese e vice-versa.
}

No entanto, o português que define diversas comunidades linguísticas brasileiras, entre elas a comunidade surda, é diminuído, tornado língua "errada", como embate das políticas linguísticas orientadas pela ideologia colonial de língua pura contra as lutas de resistência dos indígenas, quilombolas, surdos, entre outros povos. Olhar para o português do(a) surdo(a) é, portanto, ver as inscrições das lutas de um povo historicamente subalternizado por uma língua (português colonial) que supostamente deveria falar.

Essas lutas resultaram, sem dúvidas e vemos isso nos diversos movimentos das pessoas surdas em defesa do direito a uma educação escolar que contemple suas 


\title{
ITHerarius REFLECTIONIS
}

Revista Eletrônica de Graduação e Pós-Graduaçāo em Educaçäo

especificidades linguísticas, na reexistência sociolinguística e socioidentitária da pessoa surda. São esses movimentos políticos de reexistência que vêm fortalecendo as pessoas surdas contra um sistema educacional que nega os seus direitos linguísticos, prometendo garantir o direito ao acesso à informação, ao pertencimento, e pior, o direito à humanidade.

\begin{abstract}
Estes olhares que os europeus trouxeram para cá revelaram que seus interesses estavam acima da real intenção de encontrar-se com nossos antepassados. Eles não tiveram consideração por nossos olhares e logo mostraram suas verdadeiras intenções de domínio, de riqueza fácil. Para isso não se furtaram de querer aprisionar nossos avós, roubar-lhes os conhecimentos tradicionais e tentar tirar de dentro de nós nossa forma de escrever nossa própria escrita. Quiseram roubar - $\mathrm{e}$ em muitos casos conseguiram - nossa alma colocando em seu lugar um espírito que nunca foi nosso. E o que eles colocaram no seu lugar? Necessidades que não eram nossas. Vontades que não tínhamos; desejos que não desejávamos; ódio que não sentíamos; bens que não nos pertenciam; pensamentos que não pensávamos. Foram plantando no coração de nossos antepassados um desejo de não Ser. (MUNDURUKU, [s.d.], ênfase adicionada)
\end{abstract}

A historiografia linguística indígena e surda brasileira revela muitas atrocidades políticas para subtração de diversas línguas indígenas e de sinais "pela imposição da língua de dominação" (REZENDE, 2011) como estratégias para anulação dos povos. Nesse sentido, impor à pessoa surda e a todas as pessoas ouvintes o mesmo português é uma forma de negar a essas pessoas o direito ao português que é da e para cada comunidade. O resultado desse paradoxo ideológico, impor uma visão de mundo para negar outra, é a relação de dominância da população que representa a língua com posição política soberana, a que está no topo da pirâmide, e de subserviência dos demais povos, consistindo, nos termos de Ramose (2009, p. 137), em um "absolutismo dogmático" na organização linguística, política e cultural dos povos brasileiros.

O rizoma linguístico é, assim, em relação ao povo surdo, uma alternativa à tirania linguística da língua oral oficial do Brasil, pois na perspectiva rizomática um conjunto de línguas

não cessaria de conectar cadeias semióticas, organizações de poder, ocorrências que remetem às artes, às ciências, às lutas sociais. Uma cadeia semiótica é como um tubérculo que aglomera atos muitos diversos, linguísticos, mas também perceptivos, mímicos, gestuais, cogitativos: não existe língua em si, nem universalidade da linguagem, mas um concurso de dialetos, de patoás, de gírias, de línguas especiais. Não existe locutor-auditor ideal, como também não existe comunidade linguística homogênea. (DELEUZE e GUATTARI, 2011, p. 23) 
Se as comunidades linguísticas são essencialmente heterogêneas, não faz sentido estabelecer os postulados da gramática normativa como matriz de língua. Esses princípios de língua estão presentes nos materiais didáticos para ensino de português e são ensinados mesmo que não se tenha a compreensão de diversas regras por se tratar de uma língua distante das realidades sociolinguísticas de muitos povos. A reflexão linguística parte de cânones literários e desconsideram não só os diferentes contextos de uso da língua, como também as diversas populações. Esses princípios se constituem em dogmas linguísticos que todos deverão seguir.

A maioria dos(as) alunos(as) surdos(as) passa, portanto, a ser subalternizada por não dominar esse português e é submetida, conforme termos de Lemes (2012, p. 116), à "sutileza perversa da discriminação" linguística por deixarem registradas, na forma escrita, ocorrências diferentes daquelas postuladas pela norma culta do português brasileiro, que destituem o direito identitário de diversas comunidades.

Pensar a diversidade de línguas brasileiras em forma de rizoma é, portanto, uma alternativa à política de hierarquização vertical das línguas, que contribui para que as bordas do superframe sejam alargadas até que se rompam com a emergência do português de diversas outras comunidades, como vem acontecendo com o português tapuia, conforme defendido por Rodrigues (2018), da comunidade indígena Tapuia de Goiás.

O rizoma das línguas brasileiras constitui, portanto, uma alternativa à valorização da diversidade linguística do Brasil. É, pois, expandir a capacidade para perceber que na língua existe, tal qual afirma Calvet (2002, p. 65), "todo um conjunto de atitudes, de sentimentos dos falantes para com suas línguas, (...) e para com aqueles que a utiliza", e não apenas vê-la como mero "instrumento colonizatório" (SEVERO, 2016).

\section{RIZOMA LINGUÍSTICO BRASILEIRO E AS PRÁTICAS ESCRITAS EM PORTUGUÊS PELA PESSOA SURDA}

Os pesquisadores José Henrique de Freitas Santos e Ricardo Riso (SANTOS; RISO, 2013) tratam, na obra Afro-rizomas na diáspora negra: as literaturas africanas na encruzilhada brasileira, as literaturas brasileiras e as literaturas dos países africanos de língua portuguesa como sendo plurais e que, por isso, não devem estar sobrepostas, senão em 


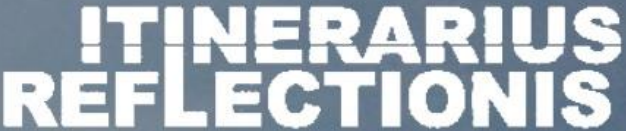

Revista Eletrônica de Graduação e Pós-Graduação em Educaçāo

diálogos que busquem reconhecer e valorizar a diversidade como forma de enfrentamento da colonialidade do poder, do saber e da linguagem.

Com base na proposta de Santos e Riso, no que se refere à necessidade de um olhar plural para aquilo que não é homogêneo, nem único, senão múltiplo como o são as literaturas, busca-se aqui uma forma de evidenciar a pluralidade linguística brasileira por meio do português do(a) surdo(a). Pensar essa língua como sendo real e que, por isso, deve fazer parte do rizoma linguístico brasileiro nos remete ao terceiro postulado discutido por Deleuze e Guattari (2011), o princípio da multiplicidade. Na visão desses autores, "é somente quando o múltiplo é efetivamente tratado como substantivo, multiplicidade, que ele não tem mais nenhuma relação com o uno como sujeito ou como objeto (...)" (ibid., p. 23).

Uma vez que por essas inúmeras línguas perpassam diferentes modos de produção de conhecimentos e de saberes, que são subalternizados pela racionalidade dualista do pensamento linguístico contemporâneo, torna-se necessário pensar em uma disposição das línguas que melhor reflita o princípio de igualdade entre os povos em relação aos direitos linguísticos, previsto na Declaração Universal dos Direitos Linguísticos de 1996 (UNESCO, 1996). Nesse sentido, a disposição rizomática das línguas surge como uma proposta política para olhar para as línguas sem sobrepô-las, rompendo, assim, com o binarismo hierarquizante que fortalece as relações de poder entre os povos. Os direitos linguísticos e identitários daqueles(as) que falam a norma culta do português brasileiro não devem estar sobrepostos aos daqueles(as) que não se encaixam nos critérios da ciência moderna que definem essa língua, excluindo vários povos.

O resultado dessa relação simétrica das diferentes formas de manifestar o envolvimento com o mundo por meio do português consiste, portanto, no fundamento de uma concepção contra-hegemônica de português como alternativa à racionalidade ocidental de português brasileiro como língua materna de todos os povos. A disposição das línguas em forma de rizoma linguístico, proposta anteriormente na figura 4, dos diferentes povos, e cada um representando o português que significa o seu próprio mundo, representa uma forma de retirar os diversos povos da condição de dominação epistêmico-linguística.

Nesse sentido, o rizoma linguístico é, além de uma proposta epistêmica e linguística, uma proposição política que cria espaços políticos (os pontos) de lutas em busca do reconhecimento e da valorização da diversidade de português no Brasil. Assim, a ideia de rizoma linguístico recoloca a geopolítica das línguas brasileiras em uma base epistêmica 


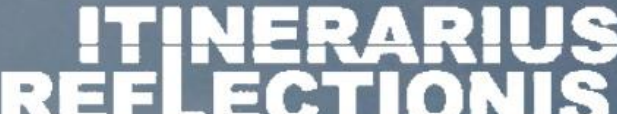 \\ REFLECTIONIS}

Revista Eletrônica de Graduação e Pós-Graduação em Educaçäo

radicada nas experiências e nos saberes de cada povo. E é nessa perspectiva rizomática que o português do(a) surdo(a) se insere entre as línguas brasileiras. Nesse sentido, o rizoma linguístico confronta os diferentes usos do português para abrir espaço e dar visibilidade a uma nova geopolítica. Nessa lógica, cada língua se "esparrama e se ajunta em consonância com diferentes formas de diáspora e conexão entre as pessoas” (PINTO, 2013, p. 141).

Cabe aqui retomar, oportunamente, uma forma de seleção e de estratificação das línguas por meio da noção de dialeto, mencionada na seção anterior. Apesar de bastante usual na Linguística, classificar uma língua como dialeto pode configurar um posicionamento político delineado por atitudes linguísticas que se empenham em diminuir a importância da língua e de inferiorização social dos(as) seus/suas falantes. Afinal de contas, o alvo do juízo de valor sobre a língua será sempre, como aponta Calvet (2002), o(a) falante. Em relação aos diferentes tratamentos políticos das línguas, esse autor destaca que a

\footnotetext{
divisão das formas linguísticas em línguas, dialetos, patoás é considerada, de maneira pejorativa, como isomorfa a divisões sociais que por sua vez também se fundam em uma visão pejorativa. À língua corresponde uma comunidade "civilizada", aos dialetos e aos patoás comunidades de "selvagens", os primeiros agrupados em povos ou em nações, os segundos, em tribos. (ibid., p. 67-68)
}

Na concepção de rizoma linguístico, defende-se a ideia de que se há pelo menos duas pessoas que interagem linguisticamente entre si, tem-se uma língua com valor e importância igual a qualquer outra. Esse posicionamento político se faz necessário diante do cenário em que se observa a manutenção de políticas linguísticas imperialistas. Nesse sentido, a noção de disposição rizomática das línguas nos possibilita refletir a estratificação linguística tanto das línguas orais como das línguas de sinais e problematizar, no segundo caso, a postura política da escola em relação à libras como língua de sinais "pura".

Ao afirmar que "o pensamento não é arborescente e o cérebro não é uma matéria enraizada nem ramificada", Deleuze e Guattari (2011) imprimem o rizoma (ou multiplicidade) como uma lógica de racionalidade. A atuação docente nos cursos de Licenciatura em Letras: Libras e de Licenciatura Intercultural para Formação Superior de Educadores Indígenas, ambos os cursos na Universidade Federal de Goiás, tem mostrado que o racionalismo científico eurocêntrico não é matriz suficientemente capaz para enquadrar o pensamento e a atuação desses povos sobre o mundo. A estrutura social ocidental liberal é, conforme visão de Deleuze e Guattari (ibid., p. 34), uma “árvore plantada na cabeça” dos(as) 


\section{ITHerarins REFLETIONIS}

Revista Eletrônica de Graduação e Pós-Graduaçāo em Educaçäo

ouvintes e dos(as) não indígenas, que saem lançando sementes de árvores na cabeça daqueles(as) que são surdos(as) e são indígenas.

Isso explica o porquê de o português da matriz curricular e de o português brasileiro não estarem representados como espaços políticos (os pontos) na representação do rizoma linguístico brasileiro apresentada anteriormente na figura 4. As instituições ainda lidam com o português como semente de uma mesma árvore que deve ser semeada em solos tão diferentes, ou seja, a colonialidade do poder, do saber e da linguagem no processo de letramento em português de comunidades linguísticas historicamente subalternizadas nos faz crer que existe uma base linguística estrutural fixa, rígida e pronta que emergirá independentemente do solo. No entanto,

é no português tapuia que a comunidade se sente, faz e se entende Tapuia, por meio da interação entre distintas gerações, pela continuidade do ensinamento de seus saberes ancestrais, por meio das tradições locais e dos causos contados ao pé do fogão, na roça ou na pamonhada. (REZENDE, 2011, p. 6)

O português $\operatorname{do}(a) \operatorname{surdo(a)}$ se caracteriza, desse modo, como a língua oral que significa a realidade da pessoa surda e que, por essa razão, não deve estar sobreposta por nenhuma outra língua, senão em coexistência com o português de outras comunidades linguísticas subalternizadas como forma de enfrentamento das diversas formas de colonialidade.

\section{CONSIDERAÇÕES FINAIS}

Com a participação das línguas indígenas, em especial as de base Tupi-Guarani, das línguas africanas bantu e yorubá, faladas pelos(as) escravos(as), e por outras línguas de emigrantes europeus e asiáticos/as, o português europeu, "língua da civilização", ou ainda "um fator de comunicação por excelência" (CARNEIRO, 2006), passou por modificações que resultou em uma diversidade de português falado pelos inúmeros povos no Brasil. Reconhecer politicamente a pluralidade linguística representa admitir que um dos processos naturais que envolvem as línguas é que elas se encontram e se reinventam, formando novas línguas e, nessa dinâmica, dão vazão à lógica plural de mundo.

A diversidade linguística entendida em forma de rizoma, e não de raiz, converge para a aproximação e para o fortalecimento de grupos em situações de vulnerabilidade 


\section{ITHepapuns REFLETIONIS}

Revista Eletrônica de Graduação e Pós-Graduaçāo em Educaçäo

linguística, cultural e política. A racionalidade rizomática abre possibilidades para entender a diferença linguística cultural e étnica como o grande valor simbólico dos povos subalternizados, ou seja, é a diferença que os aproxima, é nela que se reconhecem, é nela que se fortalecem. Somente um pensamento que compreende a "multiplicidade" é capaz de confrontar as políticas de Estado que mantêm o poder imperial por meio da linguagem.

Não cabe, portanto, subalternizar as pessoas surdas, ou qualquer outra comunidade linguística, e manter sobre elas qualquer julgo com base na crença de que o português dessas comunidades é deficitário, senão entender as diferenças nas línguas como parte fundamental na construção da identidade linguística dos povos. Por fim, o rizoma linguístico simboliza o enfrentamento à política de organização hierárquica vertical das línguas brasileiras e de seus/suas falantes e o pensamento rizomático desenha na pluralidade linguística uma geopolítica capaz de reconhecer e valorizar todos os povos e suas línguas.

Por fim, é importante deixar claro que a perspectiva rizomática de língua não tem como proposta excluir os conflitos e as resistências entre os povos, senão um ponto de encontro entre grupos linguísticos historicamente subalternizados, que persistem na luta pela desestabilização da hegemonia e da colonialidade linguística no Brasil.

\section{REFERÊNCIAS}

BAGNO, Marcos. Português ou brasileiro: um convite à pesquisa. São Paulo: Parábola, 2001.

CALVET, Louis-Jean. Sociolinguística: uma introdução. Tradução de Marcos Marciolino. São Paulo: Parábola, 2002.

CARNEIRO, Armando Teixeira. Uma visão geopolítica do espaço da língua portuguesa. Nação e Defesa, Lisboa, n. 114, 2006, p. 99-139. Disponível em: <http://www.idn.gov.pt/index.php?mod=1321\&cod=117\#sthash.RBYMfZm2.dpbs>. Acesso em: 24 jan. 2018.

DELEUZE, Gilles; GUATTARI, Félix. Mil platôs: capitalismo e esquizofrenia 2. Tradução de Ana Lúcia de Oliveira, Aurélio Guerra Neto e Célia Pinto Costa. vol. 1, 2. ed. São Paulo: Editora 34, 2011.

FARACO, Carlos Alberto. Norma-padrão brasileira. Desembaraçando alguns nós. In: BAGNO, Marcos (Org.). Linguística da norma. 3. ed. São Paulo: Edições Loyola, 2012. p. 35-56.

GARCÉS, Fernando. Las políticas del conocimiento y la colonialidad lingüística y epistémica. In: CASTROGOMEZ, Santiago; GOSFROGUEL, Ramón (Org.). El Giro 


\section{hemping \\ RIFLECTIONIS}

Revista Eletrônica de Graduação e Pós-Graduaçāo em Educaçäo

Decolonial: reflexiones para una diversidad epistémica más allá del capitalismo global. Bogotá: Universidad Javeriana-Instituto Pensar, Universidad Central-IESCO, Siglo del Hombre, 2007. P. 217-242.

JANSON, Tore. A história das línguas: uma introdução. Tradução de Marcos Bagno. 1. ed. São Paulo: Parábola Editorial, 2015.

LANDER, Edgardo. Ciências sociais: saberes coloniais e eurocêntricos. In: (Org.). A colonialidade do saber: eurocentrismo e ciências sociais. Perspectivas latino-americanas. Ciudad Autônoma de Buenos Aires: Colección Sur Sur, CLACSO, 2005.

LEMES, Sebastião de Souza. Educação, Multiculturalismo e Desigualdade. A Ação Afirmativa na Forma de Cotas Raciais para o Ensino Superior: Traços de uma Dívida Histórica e Social e a Busca da Equidade Educacional com Respeito à Democracia. In: BRABO, Tânia Suely Antonelli Marcelino; REIS, Marta dos (Org.). Educação, direitos humanos e exclusão social. São Paulo: Cultura Acadêmica, 2012.

LIMA, Hildomar José de; REZENDE, Tânia Ferreira (no prelo). Escritas em português por surdos(as) como práticas de translinguajamentos em contextos de transmodalidade. Revista de Educação Especial, Santa Maria, Dossiê - Direitos Linguísticos dos Surdos: concepções e práticas inclusivas, 2019. p. 1-24.

LIMA, Hildomar José de; REZENDE, Tânia Ferreira. Euro-ouvintismo e colonialidade epistêmico-linguística. In: CONGRESSO INTERNACIONAL - LÍNGUAS, CULTURAS E LITERATURAS EM DIÁLOGO: IDENTIDADES SILENCIADAS, 2, 2018, Brasília.

Resumos ... Brasília: UnB, 2018, p. 3-4. Disponível em: < https://docs.wixstatic.com/ugd/fe526a_5a70a6c8ae574d47989ccd03254119af.pdf>. Acesso em: 05 jan. 2019.

LUCCHESI, Dante. Língua e sociedade partidas: a polarização sociolinguística no Brasil. São Paulo: Contexto, 2015.

MIGNOLO, Walter. Epistemic disobedience, independent thought and decolonial freedom. Theory, Culture \& Society, Los Angeles, London, New Delhi and Singapore, vol. 26(7-8), p. 1-23. 2009. Disponível em: <http://journals.sagepub.com/doi/10.1177/0263276409349275>. Acesso em: 15 jun. 2018.

Histórias locais / Projetos globais: colonialidade, saberes subalternos e pensamento liminar. Tradução de Solange Ribeiro de Oliveira. Belo Horizonte: Editora UFMG, 2003.

MUNDURUKU, Daniel. A escrita e a autoria fortalecendo a identidade, [s.d.]. Disponível em: < https://pib.socioambiental.org/pt/c/iniciativas-indigenas/autoria-indigena/a-escrita-e-aautoria-fortalecendo-a-identidade>. Acesso em: 10 jan. 2017.

PINTO, Joana Plaza. Prefiguração identitária e hierarquias linguísticas na invenção do português. In: MOITA-LOPES, Luiz Paulo da (Org.). Português no século XXI: cenário geopolítico e sociolinguístico. São Paulo: Parábola Editorial, 2013. p. 120-143. 


\section{Hiparius REFLETIONIS}

Revista Eletrônica de Graduação e Pós-Graduaçāo em Educaçäo

QUIJANO, Aníbal. Colonialidade do poder e classificação social. In: SANTOS, Boaventura de Sousa; MENEZES, Maria Paula (Org.). Epistemologias do Sul. Coimbra: Almedina, 2009. p. 73-117.

Colonialidade do poder, eurocentrismo e América Latina. In:

(Org.). A

colonialidade do saber: eurocentrismo e ciências sociais. Perspectivas latino-americanas. Ciudad Autônoma de Buenos Aires: Colección Sur Sur, CLACSO, 2005.

Colonialidad del poder y classificassión social. Journal of World-Systems

Research, 6 (2), 2000, 342-386.

RAMOSE, Mogobe B. Globalização e Ubuntu. In: SANTOS, Boaventura de Sousa; MENEZES, Maria Paula (Org.). Epistemologias do Sul. Coimbra: Almedina, 2009. p. 135176.

REZENDE, Tânia Ferreira. Entre a senzala, o tijupá e a escola: a questão linguísticoidentitária entre as/os tapuia do Carretão-Goiás. In: CONGRESSO LUSO-AFRO-

BRASILEIRO DE CIÊNCIAS SOCIAIS, 11, Salvador. Anais... Salvador, 2011. p. 1-16.

RODRIGUES, Eunice Moraes da Rocha. Português Tapuia: um signo de resistência indígena. Porto das Letras, Porto Nacional, v. 4, n. 1, 2018. Disponível em:

https://sistemas.uft.edu.br/periodicos/index.php/portodasletras/issue/view/244>. Acesso em: 11 set. 2018.

SANTOS, José Henrique de Freitas; RISO, Ricardo. Afro-rizomas na diáspora negra: as literaturas africanas na encruzilhada brasileira. Rio de Janeiro: Kitabu, 2013.

SEVERO, Cristine Gorski. A invenção colonial das línguas da América. Alfa, São Paulo, v. 60, n. 1, p. 11-28, 2016.

SILVA, Luiz Antônio da . Projeto NURC: histórico. Linha D`água, São Paulo, n. 10, 1996. p. 83-90. Disponível em: < http://www.revistas.usp.br/linhadagua/article/view/37169/39890>. Acesso em: 29 jan. 2018.

UNESCO. Declaração Universal dos Direitos Linguísticos, 1996. Disponível em: <http://penclube.no.sapo.pt/pen_internacional/dudl.htm>. Acesso em 20 out. 2018. 